\title{
Effect of Repeated Firings on the Color of Porcelain: An In Vitro Study
}

\author{
B. Swapna, K. Shalini, B. Sreeramulu \\ Department of Prosthodontics, Government Dental College and Hospital, Hyderabad, Telangana, India \\ Email for correspondence: swapnamadhav@gmail.com
}

\begin{abstract}
Context: Dental ceramics are one of the widely used esthetic restorative materials and these are attractive because of their biocompatibility and long-term color stability. Duplicating the appearance of tooth structure is a complex process that requires careful control of the form, surface texture, translucency, and color of the restoration. Repeated firings of dental porcelain may change porcelain shades. Aims and Objectives: The aim of this study was to evaluate and compare the effect of multiple firings on metal ceramics before and after glazing. Materials and Methods: A total of 70 base metal alloy disks with a thickness of $0.5 \mathrm{~mm}$ were made. Then, oxidation, opaque porcelain application, and firing, followed by dentin porcelain is applied to all specimens and subjected to first and second dentin firings. They were subdivided into seven groups $(\mathrm{n}=10)$. The first group is the control group and other groups were subjected to repeated second dentin firings for $3,4,5,6,7$, and 8 dentin firings and analyzed for color with spectrophotometer. All the specimens were glazed and again analyzed for color. Results: The color difference was observed at fifth dentin firing before glazing and at eighth dentin firings after glazing compared to control group. Conclusion: Color and microhardness are noticeably affected by repeated firings.
\end{abstract}

Key words: Ceramics, color, multiple firings.

\section{INTRODUCTION}

Dental ceramics are one of the widely used esthetic restorative materials, and these are attractive because of their biocompatibility, longterm color stability, wear resistance, and their ability to be formed into precise shapes. Even though all ceramic materials are introduced as more esthetic materials these days, porcelain fused to metal restorations are frequently used due to their excellent fracture resistance and low cost compared to all ceramic materials. ${ }^{[1]}$

Duplicating the appearance of tooth structure is a complex process that requires careful control of the form, surface texture, translucency, and color of the restoration. ${ }^{[2]}$ Color is a psychophysical sensation

\begin{tabular}{|l|l|}
\hline Quick Response Code & Article Info: \\
\hline doi: 10.5866/2018.10.10021 \\
\hline $\begin{array}{l}\text { Received: 04-01-2018 } \\
\text { Revised: 29-01-2018 } \\
\text { Accepted: 08-02-2018 } \\
\text { Available Online: 15-04-2018, 2018 (www. } \\
\text { nacd.in)@ NAD, 2018 - All rights reserved }\end{array}$ \\
\hline
\end{tabular}

that results when the human visual system responds to the light reflected from objects in a scene.

When light strikes an object, a range of possible interactions such as reflection, refraction, absorption, scattering, and transmission occurs. The color replication process in dentistry comprises of shade determination phase followed by shade duplication. ${ }^{[3]}$ Duplication phase is influenced by many factors such as the method of condensation, size of the porcelain particles, stages of firing, presence of bubbles and voids, and firing temperature. ${ }^{[4]}$ There are two widely used systems for specification and coordination of color. They are Munsell system and CIE laboratory system.

Repeated firings of dental porcelain may change porcelain shades. Tylman and others state that porcelain subjected to repeated firing eventually reaches a stage of vitrification or changes into the glass. ${ }^{[5-7]}$ Therefore, the present in vitro study was designed to evaluate the effect of multiple firings on color of metal ceramics before and after glazing.

\section{Aims and Objectives}

1. The aim and objective of this study were to evaluate and compare the effect of multiple 
firings on the color stability/shade of porcelain before glazing

2. And to evaluate and compare the effect of multiple firings on the color stability/shade of porcelain after glazing.

\section{MATERIALS AND METHODS}

\section{Materials}

1. Inlay wax (Blue wax, MDM Corporation, New Delhi).

2. Sprue wax (Yeti dental).

3. Debubblizer (Uni Coat, Delta).

4. Investment material (Cobavest,Yeti dental).

5. Ni-Cr alloy (4 in all white ceramic alloy, Ivoclar).

6. Aluminium oxide abrasive (Alminox-110, 250, delta labs).

7. Opaque porcelain (A2 shade, $\mathrm{d}$ sign, Ivoclar).

8. Universal build up liquid (Delta).

9. Body porcelain (dentin A 2, powder, d sign- Ivoclar).

10. Glaze paste (Ivoclar).

11. Glaze liquid (universal- Delta).

\section{Equipment}

1. Custom-made calibrated stainless steel die (Depth micrometer).

2. P K Thomas carving set.

3. Crucible former.

4. Investing ring.

5. Muffle furnace (Technico, Technico Laboratory Products PVT LTD, Chennai, India).

6. Induction casting machine (LC -cast 60, Belgium).

7. Sand blaster (Ideal blaster, Delta, Delta Labs, India).

8. High-speed lathe (Ray Foster Dental Equipment, CA).

9. Metal trimming burs and discs.

10. Metal gauge (Essago SBC, German stainless $\mathrm{CE}$ ).

11. Ultra sonic cleanser.

12. Ceramic build up brushes (Ivoclar).

13. Ceramic furnace (programat-200, Ivoclar).

14. Spectrophotometer (spectroshade, MHT S.p.A., Via Milano 12, 37020 - Arbizzano di Negrar (VR) - Italia).

15. Microhardness testing unit (LECIA VM Auto).

\section{Methodology}

\section{Description of the Custom Made Device (Depth} Micrometer)

Depth micrometer instrument was fabricated at RVS Machine tools, Peenya industrial estate,
Bengaluru. This instrument consists of outer cylinder with an inner diameter of $10 \mathrm{~mm}$, a piston which is movable inside the cylinder and one end of this piston is attached to a rod on which main scale reading is present between $0 \mathrm{~mm}$ and $20 \mathrm{~mm}$ with $0.5 \mathrm{~mm}$ interval. Over this main scale rod, a vernier scale is attached with 50 divisions on its entire circumference. The whole piston assembly moves in the cylinder with the help of thumbscrew which is on the rear end of the vernier scale. It can be rotated clockwise or anti-clockwise. A lock is attached to the outer cylinder which helps us to lock the piston in any position while fabricating wax pattern or during the ceramic build up.

For one complete rotation of the thumb screw, the piston will move $0.5 \mathrm{~mm}$, for each division reading on the vernier scale it moves $0.01 \mathrm{~mm}$. Hence, on the whole, the piston can move, and this instrument can be used to make specimens of thickness $0.01 \mathrm{~mm}-20.0 \mathrm{~mm}$ by rotating thumb screw [Figures 1 and 2].

\section{Fabrication of Metal Backings or Discs}

A total of 70 wax patterns were fabricated using blue inlay wax with $10-\mathrm{mm}$ diameter and $0.6-\mathrm{mm}$ thickness so that $0.1 \mathrm{~mm}$ of metal can be utilized during finishing procedures to obtain uniformly thick $0.5 \mathrm{~mm}$ metal backings. The custom made device (depth micrometer) was adjusted such that, the main scale reading was at $0.5 \mathrm{~mm}$ and vernier scale reading was at 10 . In this way, $0.6 \mathrm{~mm}$ of space was created between the piston and outer sleeve of the cylinder [Figure 3].

Wax patterns were sprued using $0.2 \mathrm{~mm}$ sprue wax (Yeti dental), invested using phosphate bonded investment (Cobavest, Yeti dental) in a metal ring. The invested ring was allowed to bench set for $30 \mathrm{~min}$, (Burn out was carried out in a muffle furnace (Technico, Technico Laboratory Products

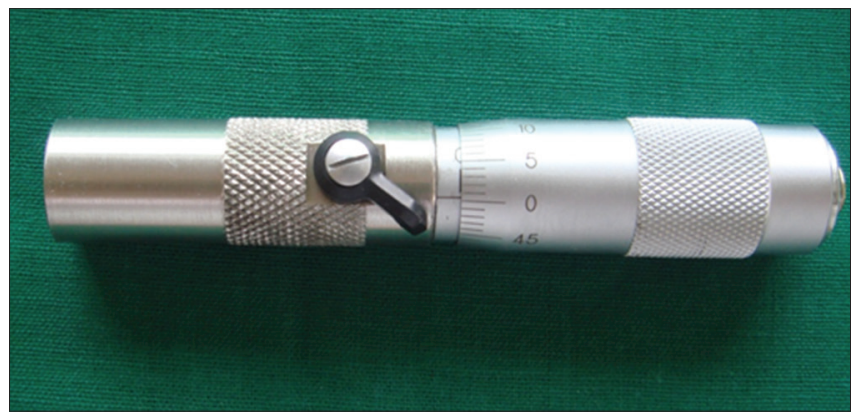

Figure 1: Custom made calibrated depth micrometer 
PVT LTD, Chennai, India) and casting was done using Nickel Chromium alloy (4 in all white ceramic alloy, Ivoclar) in induction casting machine (LC -cast 60). Once the Invested ring was cooled, it was divested, patterns were retrieved, sandblasted with aluminum oxide with particle size $110 \mu \mathrm{m}$ to obtain clean casting, then the sprues were cut.

Metal discs were trimmed carefully to obtain uniform thickness of $0.5 \mathrm{~mm}$ using finishing abrasives. The thickness was verified using metal gauge.

\section{Ceramic build up and firing}

Atotal of 70 metal discs of uniform thickness were sandblasted with aluminum oxide with particle size $55 \mu \mathrm{m}$, ultrasonically cleansed for $3 \mathrm{~min}$ and dried. They were placed in ceramic furnace (Programat 200) for oxidation, with a standby the temperature of $403 \mathrm{C}$ and gradually increased to holding the temperature of $700 \mathrm{C}$ at the rate of $30 \mathrm{C} / \mathrm{min}$ and maintained for $1 \mathrm{~min}$ before cooling [Figure 4].

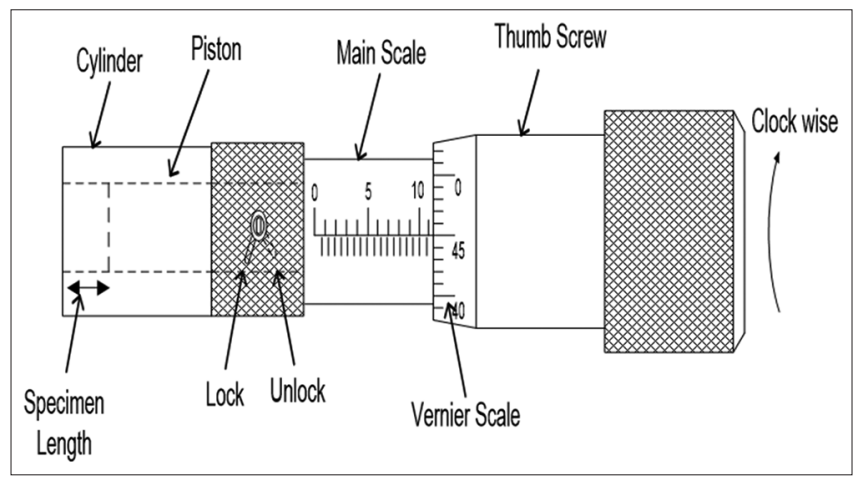

Figure 2: Line diagram of depth micrometer

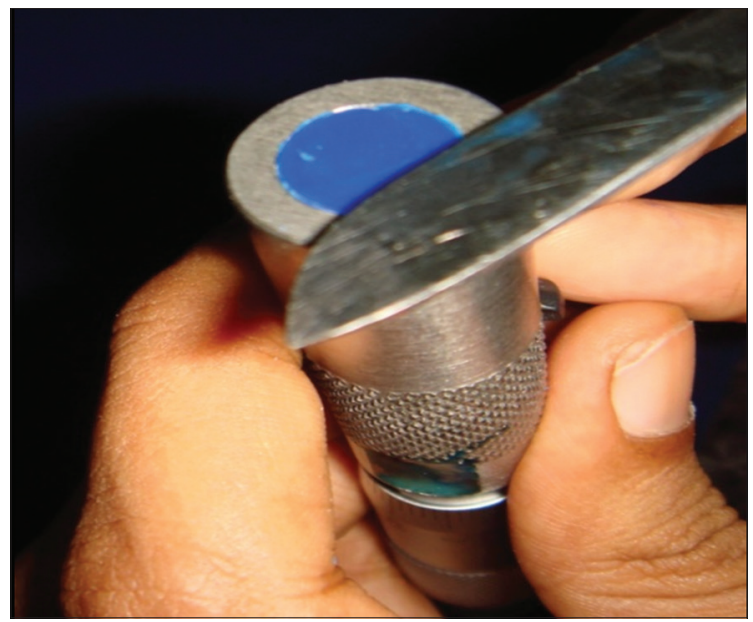

Figure 3: Wax pattern fabrication
Opaque paste (A2 shade, d sign, Ivoclar) was mixed with the opaque liquid using and evenly applied on metal discs using sable brush after cooling the metal discs to room temperature. The disc was gently vibrated so that the uniform distribution of opaque paste was achieved on the disc surface. Then, 10 specimens were placed each time on saggar tray and transferred to furnace and subjected to opaque firing [Figure 5]. The furnace was adjusted such that the holding temperature of $900 \mathrm{C}$ at a rate of $80 \mathrm{C} / \mathrm{min}$, standby temperature at $403 \mathrm{C}$, holding time $1 \mathrm{~min}$ and closing time $6 \mathrm{~min}$ $1^{\text {st }}$ vacuum applied $450 \mathrm{C}$ and $2^{\text {nd }}$ vacuum at $899 \mathrm{C}$.

\section{Dentin build up and firing}

Body dentin A2 shade (d sign, Ivoclar) was dispensed on the glass slab and mixed with modeling

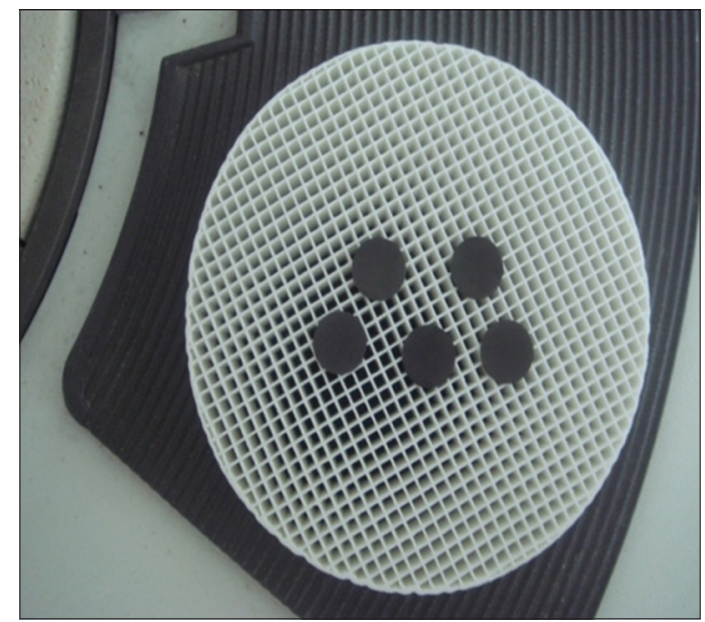

Figure 4: Oxidation of metal backing

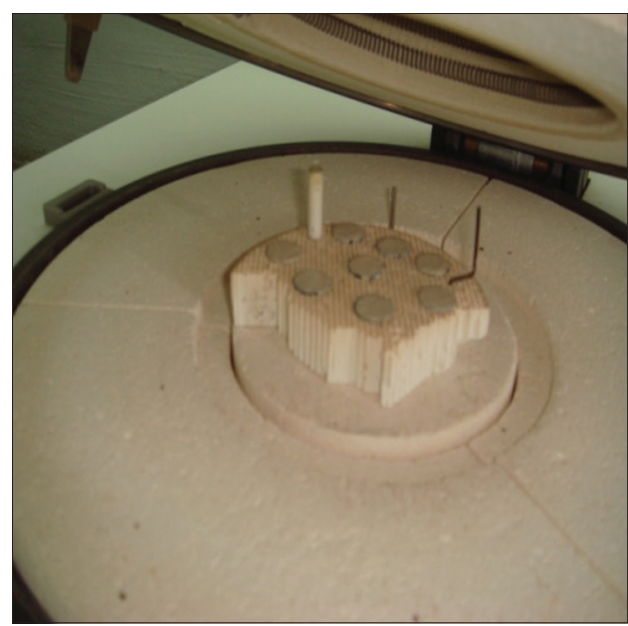

Figure 5: Opaque firing 
liquid using a ceramic spatula until the mix obtained was in working consistency. The dentin porcelain was condensed till the rim of the outer tube, and excess ceramic material was removed using ceramic spatula and smoothened. Glass plate was used to verify whether the surface was flush with rim of outer tube and ceramic was added or removed accordingly. Then, the thumb screw was rotated to raise the specimen; the specimen was carefully transferred from custom-made device to saggar by lifting with the mixing spatula [Figure 6].

First dentin firing was programmed as per the manufacturer's instructions such that the holding temperature was $870 \mathrm{C}$ at the rate of $60 \mathrm{C} / \mathrm{min}$, standby temperature at $403 \mathrm{C}$, holding time $1 \mathrm{~min}$ and closing time $9 \mathrm{~min}, 1^{\text {st }}$ vacuum applied $450 \mathrm{C}$ and $2^{\text {nd }}$ vacuum at $869 \mathrm{C}$.

After firing and cooling specimens were taken out, then thickness was measured using custom-made device and any irregularities were trimmed. Another increment of dentin was added if the thickness was $<1.5 \mathrm{~mm}$ and subjected for $2^{\text {nd }}$ dentin firing, i.e. holding temperature of $870 \mathrm{C}$, at the rate of $60 \mathrm{C} / \mathrm{min}$, holding time $1 \mathrm{~min}$, standby temperature $403 \mathrm{C}$ closing time 9 min $1^{\text {st }}$ vacuum at $450 \mathrm{C}$ and $2^{\text {nd }}$ vacuum at $869 \mathrm{C}$. Likewise, all 70 specimens were fabricated.

Once the specimens were fabricated and thickness verified, they were randomly divided into seven groups 10 in each group, $1^{\text {st }}$ group was the control group [Figure 7].

$1^{\text {st }}$ group -no extra dentin firings,

$2^{\text {nd }}$ group was subjected for 1 extra dentin firing.

$3^{\text {rd }}$ group was subjected for 2 extra dentin firings, $4^{\text {th }}$ group was subjected for 3 extra dentin firings, $5^{\text {th }}$ was subjected for group 4 extra dentin firings, $6^{\text {th }}$ group was subjected for 5 extra dentin firings, $7^{\text {th }}$ group was subjected for 6 extra dentin firings.

Once the specimens were divided and subjected to different firing cycles, all groups were color tested with spectrophotometer.

\section{Color analysis}

Description of Spectro Shade:

The Spectro Shade Micro System basically consists of:

- The spectro shade micro unit.

- Base (calibration cradle).

The spectro shade micro unit may be compared to a palmar computer, and it consists of a small

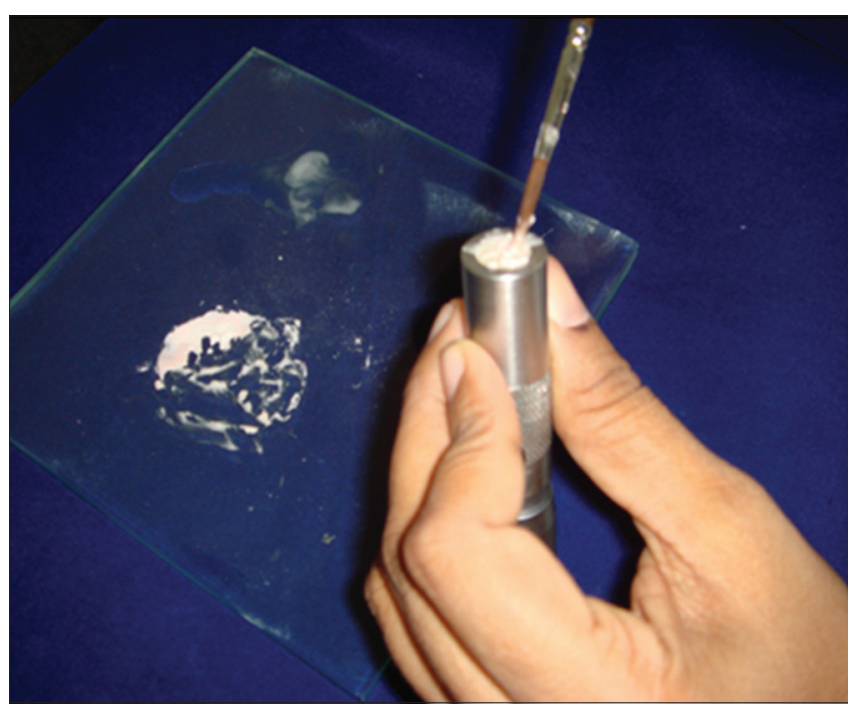

Figure 6: Ceramic condensation

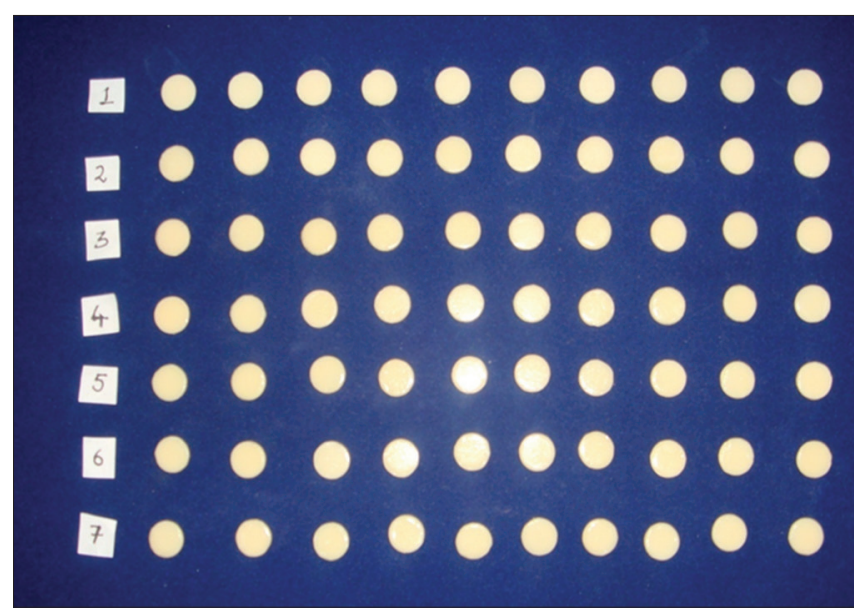

Figure 7: Specimens arranged according to groups before glazing

computer with a screen, a processor, a memory and a dedicated operating system. It has in built camera; the lens of the camera opens through a window to which the mouthpiece is attached [Figure 8].

\section{The spectro shade micro unit}

The SpectroShade Micro unit is equipped with a small display that functions like a "touch screen" on any palmar computer. The pen, which is supplied with the SpectroShade Microsystem, is situated in a special slot on the side of the display; allow us to select the commands and functions to perform

\section{Base (calibration cradle)}

The spectro shade micro unit is connected to the cradle and it rests on it. It consists of white 


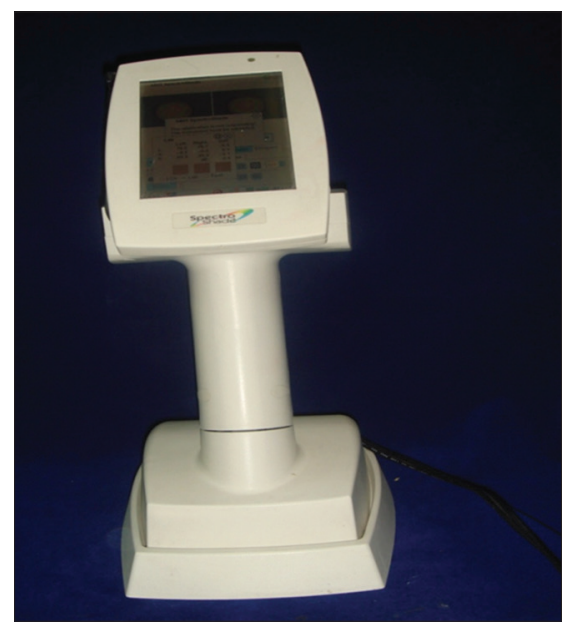

Figure 8: Spectroshade - Spectro Photometer

tile and green tile, used for calibrating the micro unit.

\section{Acquiring the image}

When the specimen being worked was in the desired position on the unit display, the measure button was pressed and released, taking care to keep the SpectroShade Micro unit still and mouthpiece at 90 angle to the target. To standardize the position of the specimen, it was mounted on the putty index which fits the mouthpiece. Then, camera tab on screen was pressed which acquires the image. The machine emits an acoustic signal if the procedure was carried out.

\section{Shade analysis}

Once the image was acquired, the shade tab was pressed, followed by "shape adjust tab," the perimeter of the image was selected and adjusted. Following this, the shade guide fed in system will be displayed appropriate shade guide was selected. Then, the whole specimen shade was analyzed, and its average shade was displayed on the screen. Then measure tab was pressed followed by this Lch scale or Lab scale tab appears on screen, Lab tab was pressed it gives the reading in Lab scale. Thus, the shade was analyzed and tabulated.

\section{Glazing}

Then, glaze paste (Ivoclar) mixed with glaze liquid (Ivoclar) was applied for all specimens with ceramic brush. Glaze firing, i.e. holding temperature of $830 \mathrm{C}$, at the rate of $60 \mathrm{C} / \mathrm{min}$, holding time $1 \mathrm{~min}$, standby temperature $403 \mathrm{C}$, closing time $4 \mathrm{~min}$ $1^{\text {st }}$ vacuum at $450 \mathrm{C}$, and $2^{\text {nd }}$ vacuum at $829 \mathrm{C}$ was done. Likewise, all groups of specimens (70) were glazed and again color was analyzed.

\section{RESULTS}

Color was analyzed in CIE L*a*b*scale, where $\mathrm{L} *$ coordinate represents the brightness of an object, its value between 0 and 100 in which 0 representing white and 100 - black. a* coordinate ranges from -90 to +70 , positive value for red and negative for green. $b^{*}$ coordinate ranges from -80 to +100 , positive value for yellow and negative value for blue.

\section{Statistical analysis}

The tabulated values of color, i.e., $L^{*}, a^{*}, b^{*}$ were separately subjected to statistical analysis by t-test to know any significant difference between the two values. The "mean," "standard deviation" was calculated for each group and each color coordinate. Then, the values were compared with control group and changes from baseline, percentage of change, and P-values were calculated. The color difference between control group and test groups were calculated and tabulated in the following tables.

In the present study, the $L^{*}$ coordinate value of the specimens before glazing of group $3(74.74$ $\pm 1.03)$ and group $4(75.20 \pm 0.52)$ has shown statistically significant change from control group $(76.00 \pm 0.89)$ [Table 1]. The $L^{*}$ coordinate value of the specimens after glazing of Group $4(74.30$ \pm 0.72 ) has shown statistically significant change from control group [Table 2].

The "a*"coordinate value of the specimens before glazing of group $2(0.88 \pm 0.43)$, Group 6 $(0.51 \pm 0.60)$, Group 7 ( $0.89 \pm 0.57)$ has shown statistically significant change from control group $(0.08 \pm 0.55) \quad$ [Table 3]. Moreover, after glazing statistically significant change of "a*" coordinate value from control group ( $0.20 \pm 0.64)$ was seen in Group 7 ( $0.95 \pm 0.54)$ [Table 4].

The " $b *$ " coordinate value of the specimens before glazing of Group $2(19.49 \pm 1.11)$, group $3(21.80 \pm$ 1.13), Group 4 (22.73 \pm 0.74$)$, Group 5 (21.99 \pm 0.86$)$, and Group $7(21.58 \pm 0.85)$ has shown statistically significant change from control group $(20.86 \pm 0.4521)$ [Table 5] and after glazing statistically significant change of " $\mathrm{a} *$ " coordinate value from control group $(21.94 \pm 0.57)$ was seen in Group $3(21.05 \pm 0.95)$ and Group $7(20.60 \pm 0.70)$ [Table 6].

Color difference was calculated using the formula given by Clarke

$$
\mathrm{E}=\left[\left(\mathrm{L}^{*}\right)^{2}+\left(\mathrm{a}^{*}\right)^{2}+\left(\mathrm{b}^{*}\right)^{2}\right]^{1 / 2}
$$


Table 1: The $L^{*}$ value of the specimens before glazing

\begin{tabular}{lcccc} 
Before glazing & $\boldsymbol{L}^{*}$ value mean \pm SD & Change from baseline & \% change from baseline & P \\
\hline Group 1 Control group & $76.00 \pm 0.89$ & - & - & 0.86 \\
Group 2 & $75.35 \pm 0.93$ & $0.65 \pm 0.04$ & 1.66 & $0.125(\mathrm{NS})$ \\
Group 3 & $74.74 \pm 1.03$ & $1.26 \pm 0.14$ & 1.05 & $0.009(\mathrm{~S})$ \\
Group 4 & $75.20 \pm 0.52$ & $0.80 \pm 0.37$ & 1.05 & $0.026(\mathrm{~S})$ \\
Group 5 & $75.20 \pm 1.33$ & $0.80 \pm 0.44$ & 0.53 & $0.131(\mathrm{NS})$ \\
Group 6 & $75.60 \pm 0.98$ & $0.40 \pm 0.09$ & 1.14 & $0.346(\mathrm{NS})$ \\
Group 7 & $75.13 \pm 1.06$ & $0.87 \pm 0.17$ & $0.060(\mathrm{NS})$ \\
\hline
\end{tabular}

NS: Non significant, SD: Standard deviation

Table 2: The $L^{*}$ value of the specimens after glazing

\begin{tabular}{lcccc} 
After glazing & ${ }^{*} \boldsymbol{*}^{*}$ value mean $\pm \mathbf{S D}$ & Change from baseline & \% change from baseline & $\boldsymbol{P}$ \\
\hline Group 1 Control group & $75.20 \pm 0.79$ & - & - & - \\
Group 2 & $75.10 \pm 0.83$ & $0.10 \pm 0.04$ & 0.13 & $0.786(\mathrm{NS})$ \\
Group 3 & $74.42 \pm 1.08$ & $0.78 \pm 0.29$ & 1.04 & $0.083(\mathrm{NS})$ \\
Group 4 & $74.30 \pm 0.72$ & $0.90 \pm 0.07$ & 0.49 & $0.016(\mathrm{~S})$ \\
Group 5 & $74.83 \pm 1.20$ & $0.37 \pm 0.41$ & 0.11 & $0.422(\mathrm{NS})$ \\
Group 6 & $75.28 \pm 1.03$ & $-0.08 \pm 0.24$ & 0.05 & $0.848(\mathrm{NS})$ \\
Group 7 & $74.81 \pm 0.75$ & $0.39 \pm 0.04$ & $0.272(\mathrm{NS})$ \\
\hline
\end{tabular}

NS: Non significant, SD: Standard deviation, S: Significant

Table 3: The $a^{*}$ value of the specimens before glazing

\begin{tabular}{lccc} 
Before glazing & $\mathbf{a}^{*}$ value mean \pm SD & Change from baseline & P \\
\hline Group 1 Control group & $0.08 \pm 0.55$ & - & - \\
Group 2 & $-0.88 \pm 0.43$ & $0.96 \pm 0.12$ & 0.000 (S) \\
Group 3 & $-0.33 \pm 0.49$ & $0.41 \pm 0.06$ & 0.101 (NS) \\
Group 4 & $-0.37 \pm 0.72$ & $0.45 \pm 0.17$ & 0.140 (NS) \\
Group 5 & $-0.56 \pm 0.95$ & $0.64 \pm 0.40$ & $0.086(\mathrm{NS})$ \\
Group 6 & $-0.51 \pm 0.60$ & $0.59 \pm 0.05$ & $0.037(\mathrm{~S})$ \\
Group 7 & $-0.89 \pm 0.57$ & $0.97 \pm 0.02$ & $0.001(\mathrm{~S})$ \\
\hline
\end{tabular}

Statistically significant $=P<0.05$. NS: Nonsignificant, SD: Standard deviation, S: Significant

Table 4: The a*value of the specimens after glazing

\begin{tabular}{lccc} 
After glazing & $\mathbf{a}^{*}$ value mean \pm SD & Change from baseline & P \\
\hline Group 1 Control group & $-0.20 \pm 0.64$ & - & $0.25 \pm 0.25$ \\
Group 2 & $-0.45 \pm 0.39$ & $0.26 \pm 0.11$ & 0.316 (NS) \\
Group 3 & $-0.46 \pm 0.53$ & $0.58 \pm 0.19$ & 0.348 (NS) \\
Group 4 & $-0.78 \pm 0.83$ & $0.58 \pm 0.31$ & $0.102(\mathrm{NS})$ \\
Group 5 & $-0.78 \pm 0.95$ & $0.15 \pm 0.17$ & 0.131 (NS) \\
Group 6 & $-0.35 \pm 0.47$ & $0.75 \pm 0.10$ & $0.573(\mathrm{NS})$ \\
Group 7 & $0.95 \pm 0.54$ & & $0.012(\mathrm{~S})$ \\
\hline
\end{tabular}

NS: Non significant, SD: Standard deviation, S: Significant 
Between the control group and test groups, the color difference of 1.795 units for Group 2, 1.625 units for Group 3, 2.083 units for Group 4, 1.525 units for Group 5, 1.228 units for Group 6, and 1.489 units for Group 7 were noticed from control group before glazing [Table 7].

The color difference of 0.354 units for Group 2, 1.212 units for Group 3, 1.102 units for Group 4, 0.868 units for Group 5, 0.270 units for Group 6, and 1.584 units for Group 7 was noticed from control group after glazing [Table 8].

\section{DISCUSSION}

The ultimate goal of restorative dentistry is to restore missing tooth structure to natural form, function, and appearance. Duplicating the appearance of tooth structure is a complex process that requires careful control of form, surface texture, translucency, and color of the restoration. A significant variation in any one of these factors will alter the overall appearance of the restoration and result in patient dissatisfaction. While each of these factors may be considered of equal importance to the overall appearance of a restoration, it appears that errors associated with color account for significant proportion of variability that occurs in duplication process.

The factors that have an influence on the final color of dental porcelain include type of alloy

\begin{tabular}{lcccc} 
Table 5: The $b^{*}$ value of the specimens before glazing. & & \\
Before glazing & $\boldsymbol{b}^{*}$ value mean \pm SD & Change from baseline & \% change from baseline & P \\
\hline Group 1Control group & $20.86 \pm 0.45$ & - & - & - \\
Group 2 & $19.49 \pm 1.11$ & $-1.37 \pm 0.66$ & 4.51 & $0.004(\mathrm{~S})$ \\
Group 3 & $21.80 \pm 1.13$ & $-0.94 \pm 0.68$ & 8.96 & $0.032(\mathrm{~S})$ \\
Group 4 & $22.73 \pm 0.74$ & $-1.87 \pm 0.29$ & 5.42 & $0.000(\mathrm{~S})$ \\
Group 5 & $21.99 \pm 0.86$ & $-1.13 \pm 0.41$ & 4.79 & $0.003(\mathrm{~S})$ \\
Group 6 & $21.86 \pm 1.40$ & $-1.00 \pm 0.95$ & 3.45 & $0.055(\mathrm{NS})$ \\
Group 7 & $21.58 \pm 0.85$ & $-0.72 \pm 0.40$ & $0.032(\mathrm{~S})$ \\
\hline
\end{tabular}

Statistically significant $=P<0.05$. NS: Nonsignificant, SD: Standard deviation, S: Significant

Table 6: The $b^{*}$ value of the specimens after glazing

\begin{tabular}{|c|c|c|c|c|}
\hline After glazing & $b^{*}$ value mean $\pm S D$ & Change from baseline & $\%$ change from baseline & $\boldsymbol{P}$ \\
\hline Group 1 Control group & $21.94 \pm 0.57$ & - & - & - \\
\hline Group 2 & $22.17 \pm 1.12$ & $-0.23 \pm 0.55$ & 1.05 & $0.565(\mathrm{NS})$ \\
\hline Group 3 & $21.05 \pm 0.95$ & $0.89 \pm 0.38$ & 4.06 & $0.023(\mathrm{~S})$ \\
\hline Group 4 & $21.68 \pm 0.98$ & $0.26 \pm 0.41$ & 1.19 & 0.481 (NS) \\
\hline Group 5 & $21.41 \pm 0.90$ & $0.53 \pm 0.33$ & 2.42 & $0.141(N S)$ \\
\hline Group 6 & $21.73 \pm 0.96$ & $0.21 \pm 0.39$ & 0.96 & $0.571(N S)$ \\
\hline Group 7 & $20.60 \pm 0.70$ & $1.34 \pm 0.13$ & 6.11 & $0.000(S)$ \\
\hline
\end{tabular}

NS: Non significant, SD: Standard deviation, S: Significant

Table 7: The overall color difference and comparison between the control group and test groups before glazing

Color difference was calculated using the formula: $E=\left[\left(L^{*}\right)^{2}+\left(\Delta \mathbf{a}^{*}\right)^{2}+\left(\Delta \mathbf{b}^{*}\right)^{2}\right]^{1 / 2}$

\begin{tabular}{|c|c|c|c|}
\hline$\left(\Delta L^{*}\right)^{2}$ & $\left(\Delta \mathbf{a}^{*}\right)^{2}$ & $\left(\Delta b^{*}\right)^{2}$ & $\Delta E$ \\
\hline$\left(\text { group } 1 L^{*}-2 L^{*}\right)^{2}=0.42$ & $\left(\text { group } 1 a^{*}-2 a^{*}\right)^{2}=0.92$ & $\left(\right.$ group $\left.1 b^{*}-2 b^{*}\right)=1.88$ & 1.795 \\
\hline$\left(\text { group } 1 L^{*}-3 L^{*}\right)^{2}=1.59$ & $\left(\text { group } 1 a^{*}-3 a^{*}\right)^{2}=0.17$ & $\left(\text { group } 1 b^{*}-3 b^{*}\right)^{2}=0.88$ & 1.625 \\
\hline$\left(\text { group } 1 L^{*}-4 L^{*}\right)^{2}=0.64$ & $\left(\text { group } 1 a^{*}-4 a^{*}\right)^{2}=0.20$ & $\left(\text { group } 1 b^{*}-4 b^{*}\right)^{2}=3.50$ & 2.083 \\
\hline$\left(\text { group } 1 L^{*}-5 L^{*}\right)^{2}=0.64$ & $\left(\text { group } 1 a^{*}-5 a^{*}\right)^{2}=0.41$ & $\left(\text { group } 1 b^{*}-5 b^{*}\right)^{2}=1.28$ & 1.525 \\
\hline$\left(\text { group } 1 L^{*}-6 L^{*}\right)^{2}=0.16$ & $\left(\text { group } 1 a^{*}-6 a^{*}\right)^{2}=0.35$ & $\left(\text { group } 1 b^{*}-6 b^{*}\right)^{2}=1.00$ & 1.228 \\
\hline$\left(\text { group } 1 L^{*}-7 L^{*}\right)^{2}=0.76$ & $\left(\text { group } 1 a^{*}-7 a^{*}\right)^{2}=0.94$ & $\left(\text { group } 1 b^{*}-7 b^{*}\right)^{2}=0.52$ & 1.489 \\
\hline
\end{tabular}


Table 8: The overall color difference and comparison between the control group and test groups after glazing

\begin{tabular}{lccc}
$(\boldsymbol{\Delta})^{2}$ & $\left(\boldsymbol{\Delta \mathbf { a } ^ { * } ) ^ { 2 }}\right.$ & $(\boldsymbol{\Delta b})^{2}$ & $\Delta \boldsymbol{E}$ \\
\hline$(\text { group } 1 L-2 L)^{2}=0.01$ & $\left(\text { group } 1 \mathrm{a}^{*}-2 \mathrm{a}^{*}\right)^{2}=0.06$ & $\left(\text { group } 1 b^{*}-2 b^{*}\right)^{2}=0.05$ & 0.354 \\
$(\text { group } 1 L-3 L)^{2}=0.61$ & $\left(\text { group } 1 \mathrm{a}^{*}-3 \mathrm{a}^{*}\right)^{2}=0.07$ & $\left(\text { group } 1 b^{*}-3 b^{*}\right)^{2}=0.79$ & 1.212 \\
$(\text { group } 1 L-4 L)^{2}=0.81$ & $\left(\text { group } 1 \mathrm{a}^{*}-4 \mathrm{a}^{*}\right)^{2}=0.34$ & $\left(\text { group } 1 b^{*}-4 b^{*}\right)^{2}=0.07$ & 1.102 \\
$(\text { group } 1 L-5 L)^{2}=0.14$ & $\left(\text { group } 1 \mathrm{a}^{*}-5 \mathrm{a}^{*}\right)^{2}=0.34$ & $\left(\text { group } 1 b^{*}-5 b^{*}\right)^{2}=0.28$ & 0.868 \\
$(\text { group } 1 L-6 L)^{2}=0.01$ & $\left(\text { group } 1 \mathrm{a}^{*}-6 \mathrm{a}^{*}\right)^{2}=0.02$ & $\left(\text { group } 1 b^{*}-6 b^{*}\right)^{2}=0.04$ & 0.270 \\
$(\text { group } 1 L-7 L)^{2}=0.15$ & $\left(\text { group } 1 \mathrm{a}^{*}-7 \mathrm{a}^{*}\right)^{2}=0.56$ & $\left(\text { group } 1 b^{*}-7 b^{*}\right)^{2}=1.0$ & 1.584 \\
\hline
\end{tabular}

substructure being more change observed for base metal and palladium silver alloys than noble metal alloys; particle size of ceramic firing conditions such as air firing has more effect on color change than vacuum firing; thickness of the restoration pertaining to particular shade. ${ }^{[5-11,13]}$

Then, number of firings as a potential source of variation was investigated by number of researchers; the effect is negligible when repeated firings is up to 5 , after 5 firings effect is seen but less after subsequent firings. ${ }^{[4,5]}$ This was attributed to loss of auto glaze in porcelain, increase in density due to decrease in air bubbles trapped inside the porcelain. ${ }^{[8,9]}$

Tylmann reported that higher or repeated firing cycles changed the color of porcelain, because eventually it reaches a stage of vitrification or changes into glass, once this point is reached continued firing will produce overglazing and loss of color and contour accompanied by glassy appearance..$^{[14]}$

Many color assessment studies done before 1980 's are noncolorimetric. They were done visually so subjected to physio-psychological effect of vision. ${ }^{[4,5,7,8]}$ Instrumental measurements can quantify color and allow communication to be more uniform and precise. Electronic color measuring instruments, such as spectrophotometers, spectroradiometers measure light reflectance at wavelength intervals over the visible spectrum.

Spectrophotometer measures the reflectance or transmittance factors of an object one wavelength in time. They have been used to measure the spectral curves of porcelain and extracted teeth. ${ }^{[9]}$

Although the previous studies focused on the variabilites affecting the final shade of porcelain they used visual assessment for metal-ceramic restorations, mostly used noble metals, recent studies are more on all ceramic, metal ceramics only limited studies with conflicting results were observed.
Therefore, the present study was done to evaluate and compare the effect of multiple firings on the color stability/shade of porcelain before glazing and after glazing.

Color difference was calculated using the formula given by Clarke

$$
\mathrm{E}=\left[(\Delta \mathrm{L} *)^{2}+\left(\Delta \mathrm{a}^{*}\right)^{2}+\left(\Delta \mathrm{b}^{*}\right)^{2}\right]^{1 / 2}
$$

The color difference $(\Delta \mathrm{E})$ represents the numerical distance between $L^{*} a^{*} b^{*}$ coordinates of two colors. When the $\mathrm{E}$ values of two colors is $<1$ unit $(\mathrm{E}<1)$ a color match between two colors can be judged. When measured the color difference were within the 1 and $2 \Delta \mathrm{E}$ unit range, correct judgments were made frequently by the observers. When $\Delta \mathrm{E}$ values were $>2$ units, all observers can apparently detect color difference between two colors. The clinically acceptable limit of color difference value is considered to be $3.7 \quad \Delta \mathrm{E}$ units. ${ }^{[2,11]}$

Between the control group and test groups, the color difference of 1.795 units for group 2, 1.625 units for group 3, 2.083 units for group 4, 1.525 units for group 5, 1.228 units for group 6, and 1.489 units for group 7 was noticed from control group before glazing.

The color difference of 0.354 units for Group 2, 1.212 units for Group 3, 1.102 units for Group 4, 0.868 units for Group 5, 0.270 units for Group 6, and 1.584 units for Group 7 was noticed from control group after glazing.

Thus, the results on color change after multiple firings is coinciding with the studies done by Barghi and Goldberg, Barghi and J.T. Richardson and; Jogrenson and R.J.Goodkind that the multiple firings has no significant effect on color visually of ceramics. ${ }^{[4,5,7]}$ More coincidence was seen with the study of Bulent Uldag ${ }^{[9]}$ where significant change was seen after five firings and less color changes was observed with subsequent firings for the two types of all ceramics they studied. They also noted 
that although significant differences were observed in $\mathrm{L}^{*} \mathrm{a} * \mathrm{~b}$ * parameters, the magnitude of mean color difference for all ceramic materials were at an acceptable perception level.

The probable reason for slight change in color after repeated firings may be attributed to lack of color stability of metal oxides during firing procedures. Various mechanisms by which different elements from the alloy may react with the adjacent porcelain, accounting for discoloration, have been reported. Bulk transfer involves the migration of the element and or its oxides from alloy into and through the interface. Surface diffusion occurs when atoms of the elements diffuse to exposed metal surface and then diffuse into the porcelain surface at porcelain metal junction. Finally, vapor deposition is a mechanism whereby elements from alloy vapourize and were subsequently deposited on to the porcelain surface resulting in discoloration. Silver is the element that has been primarily shown to be a factor in discoloration of metal ceramic alloys especially in palladium silver alloys. It vaporizes at $960 \mathrm{C}$ at atmospheric pressure. At the reduced pressure during vacuum firing dental porcelain the temperature at which vaporization occurs would be reduced. ${ }^{[12]}$

Nickel chromium and palladium alloys were widely used substructure for metal-ceramic restorations. Nickel ions were colorants that have been shown to produce a neutral grey color in sodium silicate glasses and were probably associated with color changes in porcelain. ${ }^{[10]}$

The repeated firing cause loss of auto glaze in porcelain, the increase in density caused by the decrease in air bubbles trapped inside the porcelain made a reason for slight change in color after repeated firing. ${ }^{[7]}$

Thus,inthepresentstudy, spectrophotometrically measured color differences were in acceptable range even though statistically significant difference was noticed before and after glazing.

\section{CONCLUSION}

Within the limitations of this study following conclusions were drawn,

1. The color difference observed due to repeated firings was slight and more difference was observed before glazing at $5^{\text {th }}$ firing, i.e. Group 4 compared to control group.

2. After glazing more color changes was observed at $8^{\text {th }}$ firing group7 compared to control group.

3. The $\mathrm{E}$ values in this study were between 1.2 and 2.1 units before glazing, $0.3-1.5$ units after glazing, which are in acceptable perception range $(<3.7 \mathrm{E}$ units). The color change obtained were in acceptable limit.

\section{REFERENCES}

1. Anusavice KJ. Philips Science of Dental Materials. $11^{\text {th }}$ ed. Philadelphia, PA: WB Saunders Co.; 2006. p. 655-719.

2. Seghi RR, Johnston WM, O'0Brien WJ. Performance assessment of colorimetric devices on dental porcelains. J Dent Res 1989;68:1755-9

3. Hamdan EM, Hammad IA, Tashkandi E. Evaluation of color duplication in metal ceramic complexes using visual and instrumental shade matching systems. Int J Prosthodont 2010;23:149-51.

4. Barghi N, Goldberg. Porcelain shade stability after repeated firing. J Prosthet Dent 1977;37:173-5.

5. Barghi N, Richardson JT. A study of various factors influencing shade of bonded porcelain. J Prosthet Dent 1978;39:282-4

6. Powers JM, Sakagughi RL. Craig's restorative dental materials. $12^{\text {th }}$ ed. St Louis: Mosby; 2006.

7. Jorgenson MW, Goodkind RJ. Spectrophotometric study of five porcelain shades relative to the dimensions of color, porcelain thickness, and repeated firings. J Prosthet Dent 1979;42:96-105.

8. Barghi N. Color and glaze -effect of repeated firing. J Prosthet Dent 1982;47:393-5.

9. Uludag B, Usumez A, Sahin V, Eser K, Ercoban E. The effect of ceramic thickness and number of firings on the color of ceramic systems: An in vitro study. J Prosthet Dent 2007;97:25-31.

10. Ozturk O, Uludag B, Usumez A, Sahin V, Celik G. The effect of ceramic thickness and number of firings on the color of two all-ceramic systems. J Prosthet Dent 2008;100:99-106.

11. LundTW,SchwabacherWB, GoodkindRJ.Spectrophotometeric study of the relationship between body porcelain color and applied metallic oxide pigments. J Prosthet Dent 1985;53:790-6

12. Lund PS, Piotrowski TJ. Color changes of porcelain surface colorants resulting from firing. Int J Prosthodont 1992;5:22-7.

13. Mclean JM. The science and art of dental ceramics. In: The Nature of Dental Materials and their Clinical Use. Vol 1. Deutschland; Quintessence Publishing Co.;1979. p. 23-182.

14. Tylman, Stanley D. Theory and Practice of Crown and Fixed partial Prosthodontics. 6th ed. St.Louis: Mosby; 1970. p. $562-3$. 